\title{
Representações sociais, comunicação e identidade: $o$ indígena na mídia impressa
}

\author{
Social representations, communication and identity: indigenous in the \\ print media \\ Claudomilson Fernandes Braga ${ }^{1}$ \\ (milsonprof@gmail.com) \\ Pedro Humberto Faria Campos ${ }^{2}$ \\ (pedrohumbertosbp@terra.com.br)
}

\section{Resumo}

Este estudo objetiva identificar e analisar como os sujeitos não indígenas vêem os indígenas no contexto das relações intergrupais e, particularmente, no contexto do processo de demarcação e desocupação da Reserva Indígena Raposa Serra do Sol. A pesquisa de caráter quantitativo descritivo foi realizada em um jornal de circulação nacional e os resultados indicam que as representações dos indígenas que circular (ou não), nos veículos de mídia, transcende o espaço midiático fazendo eco no espaço social, ou seja, são as vozes dos atores sociais não indígenas que ecoam nos espaços midiatizados, que, quando amplificados e legitimados pela mídia, se tornam naturalizados, e, mesmo em se tratando de situações potencialmente comunicativas, são validados como contratos de comunicação.

Palavras chave: Comunicação. Representações sociais. Conflito. Identidade.

\begin{abstract}
This study aims to identify and analyze how the subjects did not see the indigenous natives in the context of intergroup relations, and particularly in the context of the demarcation process and the unemployment reserve Raposa Serra do Sol A descriptive quantitative research study was conducted in a newspaper national circulation and the results indicate that the representations of indigenous circular (or not), the news media, the media space transcends echoing in the social space, ie, are the voices of non-indigenous social actors echoing spaces midiatizados which, when amplified and legitimized by the media, become naturalized, and even when it comes to potentially communicative situations, such contracts are validated communication.
\end{abstract}

Keywords: Communication. Social representations. Conflict. Identity.

\footnotetext{
${ }^{1}$ Doutor em Psicologia pela Pontifícia Universidade Católica de Goiás - PUC Goiás. Professor Adjunto da Faculdade de Comunicação e Biblioteconomia da Universidade Federal de Goiás. UFG.

${ }^{2}$ Doutor em Psicologia pela Université de Provence (França). Professor Titular do Programa de Pós-Graduação Stricto Sensu em Psicologia (Mestrado - Doutorado) da Pontifícia Universidade Católica de Goiás - PUC Goiás. Professor Pesquisador da UNESA (Universidade Estácio de Sá - Rio de Janeiro) e UERJ (Universidade Estadual do Rio de Janeiro). Pesquisador CNPq Nível 2.
} 


\section{Introdução}

$\mathrm{P}$ artindo das noções de que as relações intergrupais (TAJFEL, 1981), são imagens resultantes daquilo que cada grupo desenvolve a respeito de si mesmo e do outro e cujo processo de interação entre os grupos indicam representações com funções cognitivas (DOISE, 2002); que a centralidade (força) dos conteúdos relevantes, aqui compreendidas em termos e imagens que orientam a relação entre os grupos, com base em uma realidade objetiva e a sua representação subjetiva, dão aos elementos representacionais, um sentido de enunciação (CAMPOS, 2003); e que, quanto mais ativado, mais importante ele é para essa situação específica, verificamos que a mídia parece ser esse o elemento ativador que mantém essas representações e geram os processos relacionais entre os grupos.

Assim, aquilo que Moliner (1995), denomina de modelo bidimensional de representações sociais, são os elementos representacionais que indicam centralidade, e, em certa medida, muito provavelmente, compõe o núcleo central da representação dos indígenas, ou seja: a imagem que os não indígenas tem dos indígenas são resultantes de uma identidade construída, na sua quase totalidade, pelos conteúdos midiáticos.

\section{Representações sociais e comunicação}

As representações sociais descritas por Moscovici (1978) em seu livro La psychanalyse, son imagem et son public, cujo objetivo foi estudar os processos psicossociológicos existentes e subjacentes ao modo como a Psicanálise foi transformada em conhecimento do senso comum, descreve as representações sociais como "sistemas de valores, noções e práticas que proporcionam aos indivíduos os meios para orientar-se no contexto social e material [...] tornando inteligíveis a realidade física e social e integrando-se em um grupo ou em uma relação cotidiana de intercâmbios" (MOSCOVICI, 1978, p. 79).

Outro aspecto importante na compreensão do conceito de representação social é o seu papel na formação de condutas (GOMES, 2006), o que dito de outro modo significa que ela modela o comportamento e justifica sua expressão, (POESCHL, 1995; AMARAL, 1997), situando os sujeitos de forma simbólica nas relações sociais e nas categorias decorrentes das características da sociedade. 
Nesse aspecto, a idéia de modelagem do comportamento e da ação, coloca a Comunicação Social próxima da Teoria das Representações Sociais subsidiando em partes ou no todo o que Rouquette (1996) define como a compreensão dos processos de formação de conduta e a circulação das Representações Sociais nas sociedades contemporâneas, onde o fluxo comunicativo é o resultado global derivado da rede de interações que une as pessoas umas às outras (WOLF, 1999).

A partir da ideia de que os mass media descrevem e precisam a realidade exterior, apresentando à audiência uma lista daquilo sobre o que é necessário ter uma opinião (SHAW, 1979), e, portanto, prescreve a ação, logo representando um guia de leitura da realidade, dá as Representações Sociais o que Campos (2005) denomina de dimensão normativa, ou seja, as Representações Sociais definem o que é para um grupo e não para o outro assim como a Comunicação.

Nesse sentido, a noção de que o discurso da mídia é o discurso do senso comum, - elaborado e veiculado como verdade, em razão do princípio da autoridade - marca definitivamente a relação entre coisa e signo (objeto e representação) (CAMPOS, 2005), pois ambos, representação e comunicação, são essencialmente enunciados muito mais do que representações, definidos cada vez mais pelo contexto comunicacional.

Rouquette (1999), ao discutir o papel da comunicação na construção das Representações Sociais, afirma que as Representações Sociais são elaboradas e transmitidas a partir da comunicação, indicando um caminho de análise e oferecendo a Comunicação Social um lugar privilegiado na compreensão das Representações Sociais.

\section{Imagem e identidade}

Se apropriando dos conceitos de marketing sobre marca ou branding, devemos traçar duas visões distintas: uma interna e outra externa. Segundo Bender (2009, p. 171), na visão interna teremos a identidade, na visão externa, a imagem.

A primeira, a identidade, é o conceito que traçamos para uma marca, um DNA de marca planejado. São os valores e atributos que queremos passar para o mercado. A segunda, a imagem da marca, é a percepção, a maneira como a marca é percebida pela audiência. O que se faz num planejamento estratégico é, por meio do marketing e da comunicação, aproximar essas duas visões, diminuindo a dissonância cognitiva entre elas. É levar os consumidores a perceberem a marca com o valor que queremos que ela tenha. (BENDER, 2009. p. 171). 
Entretanto são as pesquisas empreendidas por Tajfel (1981), cujos estudos originalmente desenvolvidos por Sherif (1961), que a questão da identidade do grupo é colocada em debate. Para Tajfel (1981), a identidade social é "a parcela do autoconceito dum indivíduo que deriva do seu conhecimento da sua pertença a um grupo (ou grupos) social, juntamente com o significado emocional e de valor associado àquela pertença" (p. 291).

Quanto maior o sentimento de pertença, maior a tendência a diferenciar-se de maneira favorável ao seu próprio grupo (endogrupo) em detrimento do outro grupo (exogrupo). Assim, a identidade social, esse sentimento de pertença, ocorre segundo Tajfel (1981), com base em três pressupostos: a) como um continuum indo do comportamento interpessoal ao comportamento intergrupal; b) a identidade social não é um ato, mas, sobretudo um processo social que se operacionaliza no interior do indivíduo, no espaço das relações individuais e no espaço das relações

institucionais; É, portanto, um processo intraindividual, interindividual e intergrupal, em um processo dialético pois o sujeito muda o comportamento com base na sua participação no grupo, mas também muda o grupo à medida que se alteram as concepções do indivíduo; e ainda: c) esse processo não ocorre no vazio, mas em um certo contexto histórico em que podem ocorrer fusões ou conflitos e, portanto, pressupõe certa organização social, estrutural e de legitimidade e estabilidade.

Os pressupostos apresentados por Tajfel (1981) possibilitam compreender que a identidade social pode ser compreendida como um sentimento de pertença, portanto, de crença na pertença (DEL PRETTE \& DELPRETTE, 2003). Por mudança social, pode-se entender "um movimento social que representa um esforço de um grande número de pessoas para resolver coletivamente um problema sentido como comum" (TAJFEL, 1981. p. 277). Por outro lado a mobilidade social é, segundo Tajfel (1981), “o movimento dos indivíduos, famílias e grupos de uma posição social para outra" (p. 277). Assim, as crenças na mobilidade social, abrindo perspectivas de ascensão social individual, estimulam estratégias individualistas de ação (comportamentos interindividuais), ao passo que as crenças na mudança social favoreceriam estratégias coletivas (comportamentos intergrupais). Dessa forma, em ambos os casos, a relação entre crenças e ação é mediada pelos processos de identidade social e diferenciação grupal.

\section{Método, amostra e procedimentos}

A pesquisa caracterizada como quantitativa do tipo descritiva foi realizada na cidade de Normandia, estado de Roraima, entre os dias 21 e 25 de abril de 2011. Localizada na denominada 
Microrregião Nordeste do Estado de Roraima, a $185 \mathrm{~km}$ da capital, Boa Vista, Normandia possui uma densidade populacional que não ultrapassa 0.97 habitantes por $\mathrm{km}^{2}$, segundo dados do censo 2010 (IBGE).

Normandia tem, segundo dados do censo de 2010 uma população de 8.926 habitantes (IBGE, 2010), dos quais aproximadamente 92\% eram indígenas ou descendentes diretos no máximo de segunda geração. Do total de habitantes, 4.670 eram do sexo masculino e 4.256 do sexo feminino, e apenas 2311 residiam na área urbana do município. Os demais 6.616 viviam na zona rural que possui $7.008 \mathrm{~km}^{2}$ de área.

Classificada como probabilística por conveniência, a amostra foi composta por 50 sujeitos não indígenas residentes na área urbana do município de Normandia (RR), sendo $22 \%$ do sexo masculino, $78 \%$ feminino. A faixa etária média dos entrevistados era de 28 anos.

O instrumento elaborado com perguntas fechadas de múltipla escolha, do tipo Likert, possibilitou aos entrevistados indicarem seu grau de concordância ou discordância, as declarações relativas à atitude investigada, uma vez que a escala de Likert atribui valores numéricos e/ou sinais as respostas que refletem a força e a direção da reação do entrevistado à declaração. A escala de Likert permite que, declarações de concordância recebam valores positivos ou altos, ao passo que as declarações das quais discordam recebam valores negativos ou baixos (BAKER, 2005).

As respostas situam-se nos seguintes extremos: $\mathbf{1}=$ discordo totalmente e $\mathbf{7}=$ concordo totalmente, cujos valores intermediários foram assim descritos: $2=$ discordo parcialmente; $3=$ discordo; $4=$ nem concordo nem concordo; $5=$ concordo parcialmente e $6=$ concordo. $\mathrm{O}$ instrumento de coleta foi composto de seis blocos de questões assim delineados:

As análises dos dados foram feitas com o auxílio do software Statistical Package for the Social Sciences (SPSS), que propicia análises estatísticas descritivas e inferenciais. Com duas entradas de dados (Data View), o aplicativo permitiu desenvolver análises que demonstraram com o uso da escala Likert, quais as principais tendências de respostas dos sujeitos pesquisados, indicando a sua opinião sobre o tema perguntado. As análises executadas foram geradas observando-se um intervalo de confiança (IC) igual a 95\%, com um desvio padrão igual a 2,0 (dp=2,0\%).

Levando-se em consideração que a escala de Likert utilizada (sete pontos), os resultados foram analisados com base no valor intermediário 4, considerado, nesta análise, ponto de corte. Com os resultados da frequência de cada variável foi possível estruturar a representação gráfica dos 
resultados, indicando a curva de tendência, o que, muito provavelmente indica a centralidade das respostas.

\section{Resultados e discussões}

Os resultados indicam uma realidade típica das cidades do interior do país. O meio comunicativo preponderante na região do conflito é o radiofônico. Com um percentual superior à metade das respostas, o rádio representa o veículo de mídia mais atuante na cidade e na região. Significa, portanto, que a Folha de S. Paulo, objeto de estudo desta pesquisa como outro jornal diário, não teve penetração (direta) de audiência na região.

Apesar da existência de jornais impressos no estado de Roraima, parece ocorrer como primeira perspectiva de análise, uma situação de copy desk, ou seja, os veículos de mídia das cidades do interior e do estado de Roraima, como também das demais cidades do interior do país, reproduzem em larga escala as notícias originadas nos veículos do eixo Rio de Janeiro e São Paulo. Duas noções podem ser apontadas: a capacidade de cobertura e abrangência dessas organizações e o caráter legitimador desses veículos. Entretanto, essa análise não é completamente satisfatória e não dá conta de explicar por que o rádio é o meio comunicacional mais efetivo na região do conflito.

O fato do evento de demarcação e desocupação da RIRSS ter sido em grande parte, controlado pelo STF, emergem a figura da voz do Brasil. Criada em 1935, pelo presidente Getúlio Vargas para levar informação do poder executivo à população, a voz do Brasil à época, era o principal meio de comunicação de massa. Esse programa radiofônico, por decisão legal, conforme Lei $\mathrm{n}^{\circ}$ 4.717/62 (Brasil, 1962) deve ser reproduzido de forma obrigatória por todas as rádios existentes no Brasil entre as 19h00min e 20h00min.

Pesquisa encomendada pela Associação Brasileira de emissoras de rádio e televisão (Abert) indica a estrutura de mídia existente no país, no ano de 2008: 3.600 emissoras de rádio, 5 redes de televisão de cobertura nacional (não incluída as afiliadas), 523 jornais diários e 1.200 títulos de revista e mais de uma centena de rádios comunitárias não oficiais. A mesma pesquisa revela que a audiência radiofônica entre os horários das $19 \mathrm{~h}$ e $20 \mathrm{~h}$, atinge o percentual de $11 \%$ da população nacional. Conforme dados atualizados do censo 2010 (IBGE, 2010), 20,9 milhões de pessoas ouvem rádio nesse horário.

A pesquisa da Abert (2008) também indicou que a audiência da Voz do Brasil, no horário da sua retransmissão (19h às $20 \mathrm{~h}$ ) é de $5 \%$ da população (9,5 milhões). A essa informação acrescente- 
se que até o ano de 2010, cidades como São Paulo e municípios vizinhos não eram obrigados a retransmitir a programação no horário estipulado em razão de limitar que foi suspensa pelo STF no ano de 2010. A audiência pode ser maior do que a pesquisa indicou, explicando, portanto, a preponderância do rádio como meio comunicativo operante na região do conflito.

Veículos como a televisão também tiveram (com menor percentual) uma participação na propagação das notícias. Ao contrário da cobertura jornalística dos grandes centros, o jornal não ultrapassou $10 \%$ das respostas dadas pelos sujeitos.

Em relação à forma como as pessoas tomaram conhecimento sobre o processo de demarcação e desocupação da RIRSS, os resultados indicam que, apesar de o rádio ser o veículo midiático com maior penetração, foi mediante a informação boca a boca que o evento (ou pelo menos suas informações) se alastrou.

Tomando-se de empréstimo o entendimento de que comunicação boca a boca, caracteriza-se como uma comunicação interpessoal, em que sujeitos usuários e não usuários de um produto ou serviço compartilham experiências e opiniões a respeito dele (NICKELS \& WOOD, 1999; 2004), revelando ser confiável e não tendenciosa, e que provêm de fontes não ligadas as empresas, tais como amigos, familiares e líderes de opinião, são, normalmente, julgadas e consideradas válidas.

A comunicação boca a boca é tida como de grande relevância para modelar atitudes e comportamentos (BROW \& REINGER, 1987), em especial para a difusão de produtos, serviços ou ideias. Murray (1991), acrescenta que a comunicação boca a boca tem maior credibilidade e é mais confiável do que outros tipos, por ser acessível pelas relações sociais. Ainda, segundo a autora, essas relações tornam a comunicação boca a boca contagiosa e persistente, além de reduzir o nível de risco percebido e a incerteza, bem como apresenta relevância, pois as pessoas confiam mais nas informações pessoais do que nas não pessoais.

Diferentemente das informações midiáticas que se caracterizam como situações potencialmente comunicativas, e que, apesar de validadas a priori, são essencialmente monolocutivas (GHIGLIONE, 1984), a comunicação boca a boca pode ser considerada uma situação de contrato de comunicação, pois os interlocutores convergem para o mesmo sentido, e a informação tende a ser validada de imediato pela concordância (ou não). Dito de outro modo: a preponderância da comunicação boca a boca como o principal meio comunicacional e forma de conhecimento sobre o evento da RIRSS (48\%), em associação com o meio midiático preponderante (rádio), indicam que aquilo que circulou nos discursos entre e intragrupos foi, (ou pelo menos 
parece ter sido) a versão oficial, entendida como governamental, do processo. Trata-se do mesmo discurso reproduzido pela Folha de S. Paulo, e que tornou o indígena invisível e, portanto, silenciado.

Assim, o discurso reproduzido pela comunicação boca a boca, que em última instância representa a reprodução do discurso da mídia local (Voz do Brasil), converge e representa uma reprodução do discurso também nacional (Folha de S. Paulo), já que a prática do copy desk é uma realidade no meio midiático. Em outras palavras, mesmo que a Folha de S. Paulo não tenha chegado aos leitores da região do conflito na sua forma física (impressa), atingiu-os por meio dos discursos veiculados. Portanto, a ideia de uma situação potencialmente comunicativa, geralmente tratada como contrato de comunicação pelos veículos de massa concretiza-se, não apenas pelo sentido da legitimação, mas, sobretudo, com base na ideia de subalternidade (SPIVAK, 1994), ou seja, a voz que transita entre o locutor e o interlocutor não pertence às minorias.

Com base na expressão indutora - em relação aos indígenas, você os considera? - indicou os elementos que provavelmente compõem o núcleo central das representações do indígena. Tendo o número 4 como ponto médio de corte, em uma escala de sete pontos, os percentuais apresentados resultam da somatória dos valores válidos para cada fator investigado. Todas as respostas foram somadas em termos percentuais (válidos) com base no agrupamento em duas categorias: concordo em partes ou no todo (valores 5, 6 e 7) e discordo em partes ou no todo (valores 1, 2 e 3), sendo o valor 4 considerado nulo. Essa possibilidade interpretativa permite identificar as principais respostas e o seu nível de consensualidade, o que indica provavelmente o núcleo central da representação.

Elementos mais abstratos compreendem as cognições que determinam à identidade da representação (ABRIC, 1998). A ideia de cultura diferente parece representar o núcleo mais central das representações sociais dos indígenas. Dentre os aspectos possíveis dessa diferença cultural, a língua representa um dos mais importantes pontos (se não o mais) dessa diferenciação. Rogers e Steinfatt (1999), ao falar em diferenças interculturais com base em diferença linguística, propõem um continuиm de algumas possíveis combinações da comunicação humana, cujos pólos vão desde uma diferença cultural mínima, quando se compartilha a mesma língua, por exemplo, até a possibilidade de não haver comunicação, caso as diferenças culturais não sejam explicitadas / negociadas / traduzidas. 
Apesar da possibilidade de diferentes modos de interpretação em razão do contexto comunicativo ou do modo de ativação, os indicadores - guerreiro, aldeia, natureza, artesanato e floresta - reforçam a ideia de uma cultura não apenas diferente, mas, sobretudo distante, oposta. Ao reafirmar que as representações sociais têm uma estrutura particular, composta de crenças-nucleares que geram e gerenciam outras em uma sequência, Moscovici (2003), afirma, e de certo modo explica, como os sujeitos podem armazenar e partilhar crenças básicas (estruturantes), e, ao mesmo tempo, integrar experiências individuais (CAMPOS, 2003).

A noção do indígena que vive na selva, na floresta, que é um guerreiro e que faz artesanato (colares e cocares), permanece. Quando apenas 34\% concordam com a afirmação de que os indígenas sofrem preconceito, aparecem subjacentes às respostas à força da norma antirracista, cujos discursos tendem a aderir ao politicamente correto. Pelos discursos identificados, parece haver preconceito se diz tê-lo e não quando se atribuem determinadas características (sobretudo negativas) a determinado grupo. Quando 34\% também concordam com a afirmação de que o indígena não trabalha, e $20 \%$ os consideram selvagens (aspectos considerados como pertencentes ao sistema periférico dessa representação), parece criar-se uma barreira protetora às representações do núcleo central, dando a ideia de que não existem imagens e conceitos preconceituosos em relação aos indígenas.

De fato, os resultados da centralidade das respostas indicam uma representação do indígena que o coloca em uma posição oposta aos indivíduos não indígenas e o caracteriza como um ser natural (no sentido de pertencente à natureza), muito próximo ou mesmo inserido (completamente) na floresta. A ideia subjacente de que o lugar do indígena é na mata se mantém, sugerindo e até confirmando que a identidade indígena se aproxima em forma e conteúdo aos animais, como se fossem menos humanos. Pode-se observar, com base nos resultados que há uma indicação de infrahumanização do indígena.

Assim, o sentido de infra-humanização que ocorre em relação aos indígenas brasileiros pode ser compreendido como o que Souza (2003) denominou de subcidadania. O autor aponta que, no Brasil, ocorreu um processo de naturalização da desigualdade: "naturalização que não chega à consciência de suas vítimas, precisamente porque são construídas segundo as formas impessoais e peculiarmente opacas e intransparentes devido à ação, [...] que traveste de universal e neutro o que é contingente e particular" (SOUZA, 2003, p. 179), formando cidadãos de segunda e terceira classes. 
Redes invisíveis e objetivas que desqualificam os indivíduos e grupos sociais precarizados como subprodutores e subcidadãos constituem um fenômeno de massa, construído também pelos veículos massivos, que constroem cenários cristalizados e tendencialmente permanentes de desigualdade. Nessa perspectiva, a categoria brasileiro (SOUZA, 2003) é (re) construída, sendo possível afirmar que o processo de desigualdade no Brasil é naturalizado, mas, sobretudo, sedimentado. Desse modo, os indígenas brasileiros que são vítimas de um preconceito cordial, e muitas vezes considerados menos humanos, são na verdade resultantes de uma sociedade que, historicamente construiu contradições e revelou um processo naturalizado de gente, subgente e não gente.

Com a análise fatorial, foi possível gerar dois componentes, denominados de traços positivos e traços negativos. Os componentes negativos (manipuladores, vingativos, agressivos, perversos, preguiçosos e instintivos), quando ordenados de modo crescente, indicam, sobretudo, características de personalidade existentes nas relações intergrupais. Os componentes positivos (extrovertidos, intuitivos, criativos, solidários, inteligentes, impulsivos e hábeis fisicamente) parecem indicar características presentes apenas nas relações interindividuais e também intraindividuais.

A variável leal a sua identidade não aparece com variância explicada, o que significa que, entre os sujeitos entrevistados, não há uma concordância em relação a esse item. Explica-se em grande medida a ausência de uniformidade de respostas o fato de os sujeitos do exogrupo não terem clareza da identidade indígena, o que, de certo modo, explica também que os sujeitos pesquisados não (re) conhecem a identidade indígena.

Retomando a ideia de que o preconceito expressa especialmente um posicionamento negativo em relação a um grupo social, e que a influência de traços de personalidade, emoções e cognições são consideradas no surgimento de fenômenos dessa natureza (ALLPORT, 1979), explica, em grande parte a atribuição hostil de traços de personalidade nas relações intergrupais, alegando que os sujeitos (indígenas) pertencem a outro grupo (exogrupo). Os traços positivos existem apenas quando se trata, sobretudo, das relações intragrupais; em se tratando das relações intergrupais, prevalece a ideia de um indígena carregado de características de personalidade, podese dizer, nada nobres.

Os coeficientes obtidos, tanto nos componentes negativos quanto nos positivos, indicam uma carga fatorial elevada, demonstrando que esses componentes (1 e 2) estão carregados, ou seja, 
possuem uma carga fatorial que reflete no conjunto aquilo que os sujeitos da pesquisa pensam em relação aos indígenas.

A variância explicada resultante da análise fatorial, sobre como as demarcações de terras indígenas são percebidas pelos não indígenas, considerando que o objetivo era identificar essa percepção, deve-se em conta a proximidade de uma situação semelhante e que podem influenciar as possíveis respostas. Os resultados parecem não serem influenciados por uma situação de contato. Prevaleceram resultados decorrentes de situações potencialmente comunicativas, e as respostas dadas indicam o conteúdo que circulou na mídia. Permanece uma ambivalência explícita das respostas. O fato de atribuir aos veículos de mídia uma clara legitimação $(0,822)$, de certo modo explica os demais itens pesquisados, ou seja, as respostas dos sujeitos pesquisados indicam repetições dos conteúdos midiáticos. Essa ambivalência explicita-se no item ouvidos na demarcação (0,763-0,512). Assim, a variância (elevada) da variável autonomia é na verdade decorrente de um conjunto de percepções resultantes de uma situação comunicativa tratada e validada como contrato de comunicação.

A ambivalência das respostas representa, em última análise, uma ambivalência de sentimentos, crenças, atitude, típicos das sociedades modernas (KATZ, WACKENHUT \& HASS, 1988). Nesse sentido, o preconceito ambivalente situa a noção de conflito em um nível intrapsíquico, indicando a ambivalência entre sentimentos negativos e a força da crença na igualdade e na liberdade, apoiados por um discurso não preconceituoso.

A demarcação e desocupação da RIRSS indicam uma situação de privação relativa (do endogrupo em relação ao exogrupo) em ambos os componentes. Tomando-se de empréstimo o conceito clássico de privação relativa, desenvolvido originalmente por Merton (1957), cujo conceito, segundo o autor, o sentimento de injustiça, associado à percepção da ausência de recursos, comparando a posse desse recurso por um grupo de referência, parece existir nos não indígenas, quando afirmam que os indígenas conseguiram muito mais do que mereciam.

O sentimento de privação relativa parece se confirmar em razão da categoria de análise conseguiram muito - apresentar o maior coeficiente de correlação. Em outras palavras, em um cenário de conflito, assumir que o exogrupo perdeu ou deixou de ganhar indica aquilo que estrutura a privação relativa: eles ganharam mais do que mereciam.

As pesquisas posteriores sobre privação relativa, empreendidas por Runciman (1966) dão conta da existência de dois tipos de privação: fraterna, quando o grupo de referência normativo é 
exterior ao próprio grupo; egoísta, quando o grupo de referência normativa é o próprio grupo de pertença. Essa distinção é importante para atribuir relevância social à primeira.

Nesse sentido, a hipótese da privação relativa consegue explicar por que o não indígena, em um primeiro momento questionam as vantagens e conquistas dos indígenas no processo de demarcação e desocupação da RIRSS.

Brown (1988), reconhece a importância dessa perspectiva e afirma que a hipótese explica o fato - insólito - de grupos dominantes exprimirem descontentamento social na tentativa de reforçar ou recuperar sua estrutura/posição de dominância.

$\mathrm{Na}$ última parte do instrumento, com base na homologação da reserva pelo STF, as expressões apresentadas identificaram a dicotomia existente entre a autonomia indígena e a prevalecência da tutela. Os itens do primeiro componente (autonomia), com uma variância explicada elevada, em termos percentuais, indicam que inexiste a ideia de autonomia, mesmo em terras indígenas demarcadas. A prévia autorização do governo federal a todas as possibilidades de usos e frutos do solo, dos rios e das riquezas traduz que as etnias indígenas e, em especial as etnias da RIRSS, não possuem autonomia. Um contra senso em relação à Declaração Universal dos Direitos dos Povos Indígenas da Organização das Nações Unidas (ONU), que reconhece e estabelece aos povos indígenas o direito coletivo a terra e ao uso dos recursos naturais e à autodeterminação política. Deve-se lembrar de que a declaração foi aprovada com o voto de 143 nações, entre elas, o Brasil.

O segundo componente (tutela), cuja variância explicada dos itens também apresenta valores elevados, só reforça a ideia uma tutela extinta apenas no papel, apesar de o Congresso Nacional ter ratificado a Convenção 169 da Organização Internacional do Trabalho (OIT), que revoga a tutela indígena. O item garimpo só com autorização do Congresso não apresentou uma variância expressiva, claramente explicável: garimpagem não é atividade indígena, como ficou demonstrado no teste de centralidade. As representações do indígena estão associadas à selva, à floresta, ao artesanato, à caça, à pesca e à luta (guerra).

\section{Considerações finais}

De fato, identificam-se nos estudos capítulos de uma mesma história que se mantém (quase) inalterada. Fora da aldeia (na mídia), o indígena não se reconhece, mas, sobretudo, não é reconhecido: é invisível. Na aldeia, mantém a identidade original: caça, pesca e disputa por 
territórios. Também não é mais tutelado (pelo menos juridicamente), entretanto, ainda é um sujeito heterônomo.

Comentando o trabalho dissertativo (não publicado) de Carmo (1991), Entre a cruz e espada: o índio no discurso do livro didático de história, Van Dijk (2004), argumenta que, de fato, as representações do indígena no Brasil (e, por extensão, na América Latina), estão todas elas vinculadas à origem dos descobrimentos, ou seja, permanecem as mesmas representações existentes por ocasião da chegada dos europeus ao continente, há mais de 500 anos. "Muitas de suas características não são descritas, são na verdade comparações explícitas e implícitas com os europeus", afirma Van Dijk (2004, p. 171). Os resultados do estudo empírico corroboram aquilo que esse autor chama de associações de características do passado, e, com algumas exceções, com o presente.

Tomando de empréstimo o resultado das pesquisas empreendidas por Van Dijk (2008), em relação aos negros no Brasil. O duplo papel exercido pelo silenciamento (negação da desigualdade e homogeneização da cultura) parece fazer eco com os resultados dos estudos empreendidos pelo autor, pois assim como outras minorias, também os indígenas não aparecem nos conteúdos midiáticos. Essas constatações de fato condicionam a relação entre comunicação e representações sociais. Não se podem comunicar sem partilhar determinadas representações.

Desse modo, parece pertinente afirmar que fenômenos complexos como o preconceito são na verdade estruturas institucionais que, aparecem, sobretudo nos veículos de mídia, como situações potencialmente comunicativas, validadas como contratos de comunicação, com o objetivo de manter os discursos das elites dominantes.

Assim, os resultados desse estudo indicam que as representações sociais dos indígenas veiculadas pela mídia são, na verdade, parte de um processo de manutenção do statu quo de determinados atores sociais. Essa construção, que também é social, intenciona manter um discurso hegemônico de uma democracia racial à brasileira, toda ela construída à custa da marginalização de grupos (negros, indígenas etc.) minoritários em favor dos grupos majoritários. De fato, aquilo que se veicula na mídia indica apenas o lugar específico do grupo hegemônico: a fala, a língua, as vestes, a alimentação, a dança, dentre outros aspectos.

A identidade indígena que circula nos veículos de mídia é associada ao lugar do subalterno, silenciado (BRAGA \& CAMPOS, 2011), cuja característica aproxima-o de um sujeito menos humano, quase infra-humano. Aquilo que Souza (2003) denomina de subcidadania, em relação aos 
indígenas, é na verdade um processo de naturalização da desigualdade. A identidade social do indígena que circula nos veículos de mídia é construída segundo formas impessoais e opacas, formando cidadãos de segunda e terceira classes.

Esse fenômeno de massa que (des) qualifica determinados grupos sociais como hegemônicos, ao mesmo tempo precariza outros grupos, tornado-os invisíveis, subprodutos resultantes da massificação de um protótipo em detrimento da construção de um estereótipo. Nessa perspectiva, a categoria 'brasileiro' definida por Souza (2003) é toda ela naturalizada, sedimentada. O indígena brasileiro que é muitas vezes considerado menos humanos, é na verdade resultante de uma sociedade que, historicamente construiu contradições e revelou um processo naturalizado de gente, subgente e não gente.

Artigo submetido em 16/11/2013 e aceito em 02/12/2013.

\section{Referências}

ABRIC, J. C. A abordagem estrutural das representações sociais. Tradução de P. H. F. Campos. In: MOREIRA, A. S. P.; OLIVEIRA, D. C. (Orgs.). Estudos interdisciplinares de representação social. Goiânia: AB, 1998. p. 27-38.

ALLPORT, G. W. The nature of prejudice. New York: Addison-Wesley Publishing Company, 1988.

AMARAL, Virgílio. Níveis de análise da ancoragem das representações sociais da inteligência e do seu desenvolvimento: das posições sociais objectivas às identidades sociais. Análise Psicológica, [S.1.], v. 2, n. XV, p. 305-317, 1997.

ASSOCIAÇÃO BRASILEIRA DE EMISSORAS DE RÁDIO E TELEVISÃO. Flexibilização do programa A voz do Brasil. Disponível em: 〈http://www.abert.org.br>. Acesso em: 02 maio 2011.

BAKER, P. Gestão ambiental: a administração verde. Rio de Janeiro: Qualitymark. 2005.

BENDER, Arthur. Personal branding: construindo sua marca pessoal. São Paulo: Integrare Editora, 2009.

BROWN, Rupert. Prejudice: its social Psychology. Massachussetts: Blackwell Publishers, 1998.

CAMPOS, P. H. F. A abordagem estrutural e o estudo das relações entre práticas e representações sociais. In: .; LOUREIRO, M. C. da S. Representações sociais e práticas educativas. Goiânia: UCG, 2003. p. 22-36. 
CAMPOS, P. H. F. As representações sociais como forma de resistência ao conhecimento científico. In: .; OLIVEIRA, D. C. (Orgs.). Representações sociais: uma teoria sem fronteira. Rio de Janeiro: Museu da República Rouquette, 1999.

CARMO, S. I. S. do. Entre a cruz e a espada: o índio no discurso do livro didático de História. Dissertação de Mestrado não publicada, Faculdade de Educação da Univesidade de São Paulo. São Paulo: São Paulo, 1991.

DEL PRETTE, A.; DEL PRETTE, Z. A. Assertividade, sistema de crença e identidade social. Psicologia em Revista, Belo Horizonte, v. 9, n. 13, p. 125-136, jun. 2003.

DOISE, W. From social psychology to societal psychology. Psicologia: Teoria e Pesquisa, Brasília, v. 18, n. 1, jan./abr. 2002. Disponível em: <http://www.scielo.br/scielo.php?pid=S010237722002000100004\&script=sci_arttext\#nt01>. Acesso em: 24 jan. 2010.

GHIGLIONE, R. Situations potentiellement communicatives et contrats de communications effectifs. Verbum: Revue de Linguistique, Nancy, v. 7, p. 185-208, mar. 1984.

GOMES, M. R. As representações sociais entre estudos culturais e psicologia social. São Paulo: ECA/USP, 2008.

INSTITUTO BRASILEIRO DE GEOGRAFIA E ESTATÍSTICA. Estatística do censo 2010. Disponível em: <http://www.ibge.gov.br/home>. Acesso em: 12 jan. 2012.

MATTAR, F. N. Pesquisa de marketing. São Paulo: Atlas, 2001.

MERTON, R. K. Social theory and social structure. Glencoe: Free Press, 1957.

MOSCOVICI, S. A representação social da Psicanálise. Tradução de A. Cabral. Rio de Janeiro: Zahar, 1978.

MOSCOVICI, S. Por que estudar representações sociais em Psicologia. Estudos, vida e saúde, [S.1.], v. 30, n. 1, p. 11-30, 2003.

MURRAY, K. B. A test of services marketing theory: consumer information acquisition activities. Journal of Marketing, [S.1.], v. 55, n. 1, p. 10-25, 1991.

NICKELS, W. G.; WOOD, M. B. Marketing: relacionamentos, qualidade, valor. Rio de Janeiro: LTC. 1999-2004.

POESCHL, G. Processus d'ancrage et reprèsentations sociales de l'intelligence. Porto: Universidade do Porto. 1995.

ROGERS, E. M.; STEINFATT, T. M. Intercultural communication. Prospect Heights, IL: Waveland Press, 1999. 
ROUQUETTE. M. L. Social representation and mass communication research. Journal for the Theory of Social Behavior, [S.1.], v. 26, n. 2, p. 221-231, 1996.

RUNCIMAN, W. G. Relative deprivation and social justice. London: Routlegde and Kegan Paul, 1966.

SHAW, E. Agenda-setting and mass communication theory. Gazette International Journal for Mass Communication Studies, [S.1.], v. 25, n. 2, p. 96-105, 1979.

SHERIF, M.; et al. Intergroup cooperation and competition: the robbers cave experiment. Norman: University Book Exchange, 1961.

SPIVAK, G. Pode o subalterno falar? São Paulo: Futura, 2010.

SOUZA J. A construção social da subcidadania: para uma sociologia política da modernidade periférica. Belo Horizonte : UFMG. 2003.

TAJFEL, H. Grupos humanos e categorias sociais. Tradução de Lígia Amâncio. Lisboa: Livros Horizonte, 1981.

VAN DIJK, T. A. Dominación étnica y racismo discursivo em España y América Latina. Traducción de Montse Basté. Barcelona: Gedisa, 2004.

VAN DIJK, T. A. Racismo e discurso na América Latina. São Paulo: Contexto, 2008.

WOLF, M. Teoria da comunicação: mass media, contextos e paradigmas. 5. ed. Lisboa: Artes Gráficas, 1999. 